\title{
Evidence GDF15 Plays a Role in Familial and Recurrent Hyperemesis Gravidarum
}

\section{GDF15 spielt eine Rolle bei erblicher und wiederkehrender Hyperemesis gravidarum}

\section{(@)(1) $(9$}

Authors

Marlena S. Fejzo ${ }^{1,2}$, Daria Arzy ${ }^{1}$, Rayna Tian ${ }^{1}$, Kimber W. MacGibbon ${ }^{3}$, Patrick M. Mullin²

Affiliations

1 Division of Hematology-Oncology, David Geffen School of Medicine, University of California, Los Angeles, Los Angeles, CA, USA

2 Department of Maternal-Fetal Medicine, Keck School of Medicine, University of Southern California, Los Angeles, CA, USA

3 Hyperemesis Education and Research Foundation, Damascus, OR, USA

Key words

hyperemesis gravidarum, nausea and vomiting of pregnancy, GDF15, GFRAL, genetic

Schlüsselwörter

Hyperemesis gravidarum, Schwangerschaftsübelkeit und -erbrechen, GDF15, GFRAL, genetisch

received 13.7.2018

revised 18.7.2018

accepted 18.7.2018

Bibliography

DOI https://doi.org/10.1055/a-0661-0287

Geburtsh Frauenheilk 2018; 78: 866-870 @ Georg Thieme Verlag KG Stuttgart · New York | ISSN 0016-5751

Correspondence

Marlena S Fejzo, PhD

5535 MRL, UCLA

675 Charles E Young Dr. South, Los Angeles, CA 90095, USA mfejzo@mednet.ucla.edu

\section{ABSTRACT}

Introduction Hyperemesis gravidarum (HG), a pregnancy complication characterized by severe nausea and vomiting in pregnancy, occurs in up to $2 \%$ of pregnancies. It is associated with both maternal and fetal morbidity. HG is highly heritable and recurs in approximately $80 \%$ of women. In a recent genome-wide association study, it was shown that placentation, appetite, and the cachexia gene GDF15 are linked to HG. The purpose of this study was to explore whether GDF15 alleles linked to overexpression of GDF15 protein segregate with the condition in families, and whether the GDF15 risk allele is associated with recurrence of HG.

Methods We analyzed GDF15 overexpression alleles for segregation with disease using exome-sequencing data from 5 HG families. We compared the allele frequency of the GDF15 risk allele, rs16982345, in patients who had recurrence of HG with its frequency in those who did not have recurrence.

Results Single nucleotide polymorphisms (SNPs) linked to higher levels of GDF15 segregated with disease in HG families. The GDF15 risk allele, rs16982345, was associated with an 8fold higher risk of recurrence of HG.

Conclusion The findings of this study support the hypothesis that GDF15 is involved in the pathogenesis of both familial and recurrent cases of $\mathrm{HG}$. The findings may be applicable when counseling women with a familial history of HG or recurrent HG. The GDF15-GFRAL brainstem-activated pathway was recently identified and therapies to treat conditions of abnormal appetite are under development. Based on our findings, patients carrying GDF15 variants associated with GDF15 overexpression should be included in future studies of GDF15GFRAL-based therapeutics. If safe, this approach could reduce maternal and fetal morbidity.

\section{ZUSAMMENFASSUNG}

Einleitung Hyperemesis gravidarum (HG), das übermäßige und anhaltende Erbrechen während der Schwangerschaft, kommt in 2\% aller Schwangerschaften vor. Sie geht mit einer Erhöhung der mütterlichen und der fetalen Morbidität einher. HG ist stark vererbbar und tritt bei ungefähr $80 \%$ aller betroffenen Frauen erneut auf. In einer kürzlich durchgeführten genomweiten Assoziationsstudie konnte gezeigt werden, dass es einen Zusammenhang zwischen Plazentation, Appetit, dem Kachexie-Gen GDF15 und HG gibt. Unsere Studie wollte untersuchen, ob GDF15-Allele, die mit einer Überexpression des GDF15-Proteins einhergehen, sich in Familien zusammen mit HG vererben, und ob das GDF15-Risikoallel mit wiederkehrender HG assoziiert ist.

Methoden Die Exom-Sequenzierungsdaten von 5 Familien mit HG wurden dahingehend analysiert, ob in diesen Familien 
auch das GDF15-Überexpressions-Allel vererbt wurde. Die Häufigkeit des GDF15-Risikoallels rs16982345 bei Patientinnen mit wiederkehrender HG wurde mit der Häufigkeit bei Frauen ohne wiederkehrende $\mathrm{HG}$ verglichen.

Ergebnisse SNPs, die im Verbund mit größeren Mengen an GDF15 auftraten, vererbten sich gemeinsam mit HG in von HG betroffenen Familien. Das GDF15-Risikoallel rs16982345 ging mit einem 8-fach höheren Risiko für das Wiederauftreten von HG einher.

Schlussfolgerung Die Ergebnisse dieser Studie sprechen dafür, dass GDF15 an der Pathogenese von erblicher sowie wiederkehrender HG beteiligt ist. Das Wissen um diesen Zusam- menhang könnte bei der Beratung von Frauen mit erblicher oder wiederkehrender HG von Nutzen sein. Vor Kurzem wurde der hirnstammaktivierte GDF15-GFRAL-Weg identifiziert, und es wird aktuell an Therapien zur Behandlung von abnormem Appetitverlust gearbeitet. Gestützt auf die Ergebnisse unsere Untersuchung sollten Patientinnen mit GDF15-Varianten, die mit der Überexpression von GDF15 assoziiert sind, an zukünftigen Studien zu GDF15-GFRAL-gestützten Therapeutika teilnehmen. Sollten sich diese als sicher erweisen, könnte das ein Weg sein, um die HG-bedingte mütterliche und fetale Morbidität zu verringern.

\section{Introduction}

Nausea and vomiting of pregnancy (NVP) affects $50-90 \%$ of all pregnant women [1]. Hyperemesis gravidarum, the most severe form of NVP, occurs in $0.3-2 \%$ of pregnancies and leads to significant weight loss, dehydration, electrolyte imbalance, and ketonuria [2, 3]. It accounts for 285000 hospital discharges in the US annually [4] and is associated with maternal morbidity such as Wernicke's encephalopathy [5], renal and liver function abnormalities $[6,7]$, esophageal rupture [8], and postpartum posttraumatic stress [9]. HG is associated with a 4-fold increased risk of adverse fetal outcome including low birth weight, intrauterine growth restriction, preterm delivery, fetal and neonatal death, and a 3-fold increased risk of neurodevelopmental delay in children $[10,11]$.

A variety of potential causative factors have been investigated, with the primary hypothesis being overproduction of the pregnancy hormone human chorionic gonadotropin (hCG) [2]. There has never been sufficient evidence to support the hCG theory and a recent large retrospective cohort study provides strong evidence against it [12]. A genetic etiology to the condition is supported by familial aggregation and twin studies $[13,14]$ and our genome-wide association study shows the single-most significantly-associated genetic risk factor is GDF15, which encodes a placenta, appetite and body weight hormone [15]. GDF15 is involved in placentation and feeding behavior and is associated with cachexia, a disease with similar symptoms to HG (nausea, vomiting, weight loss, anorexia, and muscle wasting) [16-18]. In addition, the GDF15 receptor GFRAL was recently identified and is localized in the brainstem where feeding behavior, nausea and vomiting are regulated [19]. Herein we analyze GDF15, linked to HG, to provide further evidence that it may ultimately serve as a biomarker for prediction, diagnosis, and identification of novel treatments.

\section{Materials and Methods}

\section{Participants}

This study is part of an ongoing investigation evaluating the genetics and epidemiology of HG $[10,11,15]$. HG cases treated with intravenous fluids (IV) sent in saliva samples for genotyping and were asked to fill out an online survey regarding symptoms and treatments. All participants gave informed consent.

\section{Phenotype definition}

The inclusion criteria for affected individuals were a diagnosis of $\mathrm{HG}$ and treatment with intravenous (IV) fluids. The inclusion criteria for affected families was a diagnosis of HG treated with IV fluids in at least one family member, and two additional family members who reported at least 2 of the following: intravenous fluids, weight loss, medication, and/or hospitalization due to HG. Each family was asked to recruit one unaffected family member to serve as a control. Controls were eligible if they reported normal NVP or no NVP and no weight loss nor treatment for NVP in any pregnancy.

\section{Recruitment}

The source population for HG cases included patients residing in the US primarily recruited through advertising on the Hyperemesis Education and Research Foundation website [20] from 2007 to 2017. Women with a history of an HG pregnancy e-mailed the study coordinator to express their interest in participation. Minors (under 18 years) were not included in the study because few teens are expected to fit the study criteria for controls of having had two pregnancies, and it would be difficult to justify the risks/benefits to normal control minors. Because multiple gestations or chromosome abnormalities may be associated with HG due to unique physiological pathways, women with these types of pregnancies were also excluded. Each case was asked to provide medical records and fill out an online survey collecting information regarding family history, patient history, symptoms, medications, and outcomes. Participants that reported having two or more family members affected with HG were asked if they would like to participate in the family study. Participants who were interested were asked to let their family members with a pregnancy history know about the study and if they wanted to participate, to contact the study coordinator by e-mail. All participants were required to go over an information sheet by phone and return a signed information sheet with all elements of consent in order to enroll in the study.

\section{Sample collection}

Each study participant was asked to submit a saliva sample for DNA analysis. DNA Genotek saliva kits (Oragene, Ottawa, Canada) were mailed to all cases and controls. The saliva collection kit is self-administered and comes with directions for submitting $2 \mathrm{ml}$ 
of saliva into a collection vial and returning the sample to the study site via an addressed and postage-paid return envelope provided with the collection kit.

\section{Whole-exome sequencing}

Whole-exome sequencing was performed previously [21]. We sequenced the entire exomes ( $\sim 50 \mathrm{Mb})$ of 15 affected individuals and 5 unaffected individuals from $5 \mathrm{HG}$ families. Paired end reads 100 nucleotides ( $2 \times 100$ nucleotides) were generated on an Illumina HiSeq 2000. Each sample was sequenced on 3 different lanes to avoid lane bias. Qseq files were converted into Sangerformatted FASTQ files and reads were mapped to the reference human genome build hg19 using the Burrows Wheeler Alignment algorithm (BWA) [22]. Duplicated reads were marked by Picard. The Genome Analysis Toolkit (GATK) was used for local realignment around indel sites followed by a base quality recalibration [23]. For reliable SNP calling we used genotype quality $\geq 10$; read QUAL $\geq 30$ and a minimum read depth of 4 . We focused on the lead GDF15 variants associated with HG, rs16982345 and rs34345957, and the 10 variants in high ( $D^{\prime} \geq 0.9$ ) linkage disequilibrium (LD) with the lead variants (rs11881403, rs1043063, rs17725099, rs3787023, rs1058587, and rs1055150 in high LD with rs16982345; rs3195944, rs4808793, rs1227731, rs1054564 in high LD with rs3435957) that have been associated previously with altered expression of GDF15 [15]. These 12 GDF15 variants were searched for in each of the five families and analyzed to determine whether any of the variants segregated with disease (were present in all 3 affected family members but not in the unaffected family member).

\section{Recurrence definition}

Participants who were genotyped and reported a diagnosis of HG treated with IV fluids in their first pregnancy and reported HG with $>5 \%$ weight loss from pre-pregnancy weight in their second pregnancy were defined as having a recurrence. A nonrecurring HG pregnancy was defined as having HG treated with IV fluids in the first pregnancy and $\leq 5 \%$ weight loss from pre-pregnancy weight in the second pregnancy.

\section{DNA extraction}

DNA was extracted from the saliva samples according to manufacturer's instructions (Oragene, Ottawa Canada). Using the kit, we have successfully isolated, on average, $197 \mu \mathrm{g}$ of DNA of high quality (260/280 1.84) from $2 \mathrm{ml}$ of saliva. The low end of expected DNA quantity reported by the manufacturer is $30 \mu \mathrm{g} / \mathrm{ml}$ of saliva, or $60 \mu \mathrm{g} / \mathrm{sample.} \mathrm{After} \mathrm{the} \mathrm{extraction,} \mathrm{the} \mathrm{DNA} \mathrm{was}$ stored at $-20^{\circ} \mathrm{C}$.

\section{Quality control}

The TaqMan genotyping platform was performed on 384-well plates with a minimum of 2 blank samples per plate and a minimum of 2 duplicate samples per plate. Once genotypes were determined from the first 384-well plate, a minimum of 3 positive controls or one positive control for each genotype was added to the remaining plates. The minimum call rate for each SNP was $>95 \%$.

\section{Genotyping}

TaqMan genotyping primers for rs16982345 were available from Thermo Fisher Scientific and Applied Biosystems PRISM 7900HT Sequence Detection System (TaqMan) and used for screening HG cases and HG families. The call rate was $>95 \%$. Additional SNPs that have been reported to be linked to altered GDF15 levels, rs1054564 and rs1055150, were determined in the 5 families using whole-exome sequencing data as reported previously [21].

\section{Statistical analysis}

Differences in genotypes for the GDF15 HG risk locus rs 16982345 between those that had a recurrence and those that did not have a recurrence were calculated using the online odds ratio calculator available at https://www.medcalc.org/calc/odds_ratio.php, an online program which calculates p-value, odds ratio, and $95 \%$ confidence interval. The number of cases carrying the risk allele "G" (AG + GG) genotype vs. the AA genotype at rs16982345 were compared between the 119 cases that had a recurrence of $\mathrm{HG}$ and the 25 cases that did not recur.

This study was approved by the UCLA Institutional Review Board.

There are no competing financial interests.

\section{Results}

To determine whether GDF15 variants associated with altered circulating GDF15 levels segregate with disease in HG families, GDF15 variants were analyzed using existing whole-exome sequencing data from $5 \mathrm{HG}$ families [21]. Specifically, five families with three family members each whose pregnancies were affected by HG and one family member with normal NVP were genotyped to determine whether the risk alleles segregate with disease. Three SNPs associated with altered expression of GDF15 in previous studies [24-26] segregated with disease in family 1 (rs16982345), family 2 (rs1054564), and family 3 (rs1055150) ( $\vee$ Fig. 1). GDF15 variants did not segregate with disease in the family with the RYR2 mutation published previously [21]. In summary, in three of five families, the affected family members all carry genotypes that are associated with increased GDF15 levels, while the unaffected family members do not ( $\vee$ Fig. 1 ).

Finally, $144 \mathrm{HG}$ patients reporting at least 2 pregnancies were divided into two groups depending on whether they had a recurrence of HG or not. Demographic characteristics are reported in - Table 1. A recurrence was defined as having HG treated with IV fluids in the first pregnancy and HG with $>5 \%$ weight loss from pre-pregnancy weight in the second pregnancy $(n=119)$. A nonrecurring $\mathrm{HG}$ pregnancy was defined as having $\mathrm{HG}$ treated with IV fluids in the first pregnancy and $\leq 5 \%$ weight loss from pre-pregnancy weight in the second pregnancy $(n=25)$. Using this definition, $83 \%$ of women had a recurrence in their second pregnancy. Only 2 out of 119 (1.7\%) of women with HG carrying the A/A genotype at rs16982345 had a recurrence of HG, compared to 3 out of $25(12 \%)$ of the women that did not recur. The SNP rs16982345 was predictive of recurrence $(p=0.03, O R=7.98$, 1.26-50.55). The SNP rs16982345-G allele is associated with HG, and consistent with this, women with the rs16982345-AA genotype were significantly less likely to recur. 


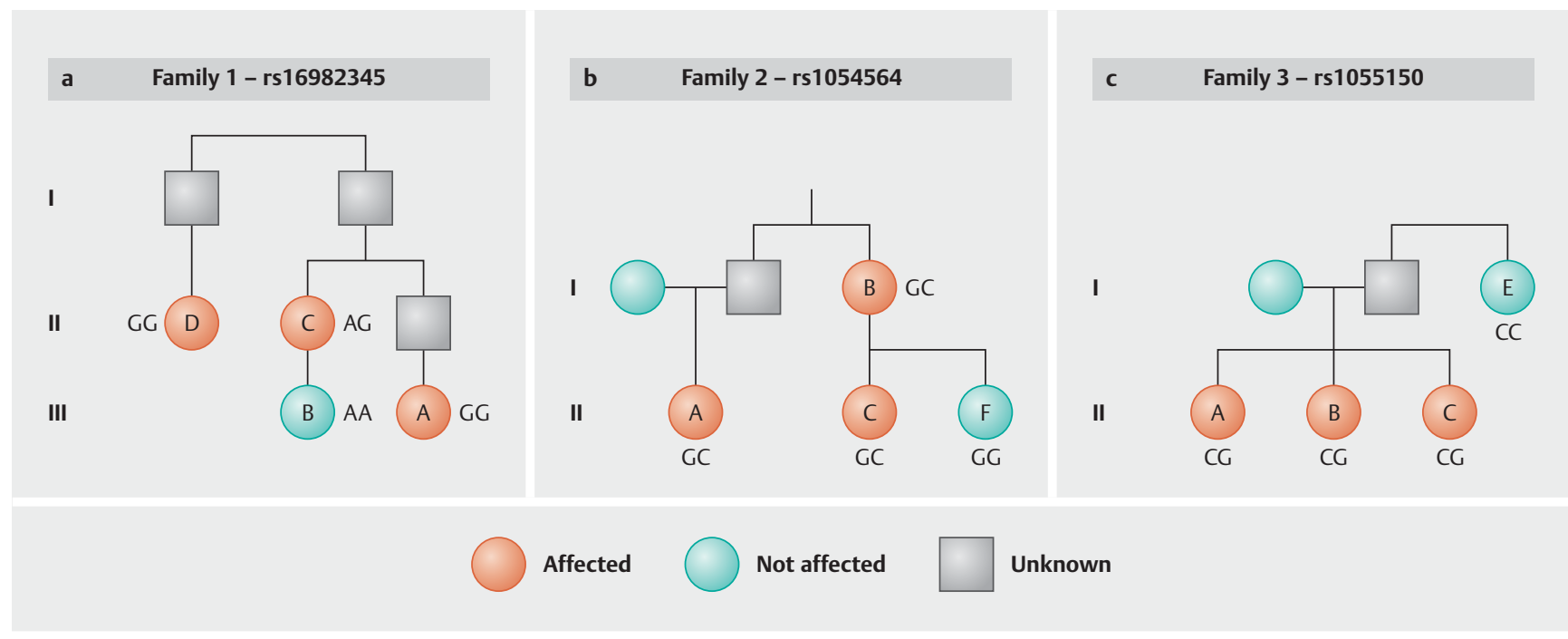

- Fig. 1 Three of five HG families show segregation of alleles at GDF15 locus associated with increased expression of GDF15. The index case is labeled with an "A" in each family. a Family 1 is of English/Irish/Swedish/Welsh descent. Case 1A reported IV fluid, total parenteral nutrition, antiemetic medication, home health care, and a > 5\% weight loss due to HG. Her cousin (1B) reported normal NVP with no weight loss and no medication to treat NVP. Her aunt (1C) reported antiemetic medication and weight loss due to HG, and her great aunt (1D) reported antiemetic medication and unrelenting nausea that kept her bedridden for 6 months due to HG. b Family 2 is of English/German/Scottish/Irish descent. Case 2A reported IV fluid, hospitalization, > 5\% weight loss, and antiemetic medication to treat her HG. Her aunt (2B) reported IV fluid, hospitalization, weight loss, and antiemetic medication to treat her HG. Her cousin (affected aunt's daughter, [2C]) reported antiemetic medication and a 24pound weight loss in the first trimester due to HG. Participant $2 \mathrm{~F}$, the unaffected sister of $2 \mathrm{C}$, reported 2 easy pregnancies with no weight loss nor treatment for NVP. c Family 3 is of English/Irish descent. Case 3A reported IV fluid, hospitalization, > $10 \%$ weight loss, and antiemetic medication to treat HG. One affected sister (3B) reported IV fluid, hospitalization, and antiemetic medication to treat HG. The other affected sister (3C) reported IV fluid, hospitalization, weight loss, and antiemetic medication to treat HG. The unaffected aunt (3E) reported mild NVP with no medication or weight loss.

- Table 1 Demographic characteristics*.

\begin{tabular}{|c|c|}
\hline Ethnicity (\% white) & $130 / 144(90.3 \%)$ \\
\hline Average maternal birth year & 1977 (1963-1989) \\
\hline Average number of HG pregnancies & $2.51(1-8)$ \\
\hline $\begin{array}{l}\text { Percent of women who voluntarily } \\
\text { terminated }\end{array}$ & $14 / 134(10.4 \%)$ \\
\hline Average number of living children & $2.02(0-5)$ \\
\hline First child (average year born) & $2004(1986-2012)$ \\
\hline Women who had vaginal deliveries & $114 / 131(87.0 \%)$ \\
\hline Women who lost one or more pregnancies & $31 / 132(23.5 \%)$ \\
\hline $\begin{array}{l}\text { Women who received partial or complete } \\
\text { higher education }\end{array}$ & $47 / 57(82.5 \%)$ \\
\hline Women who had a recurrence & $119 / 144(82.6 \%)$ \\
\hline
\end{tabular}

\section{Comment}

This is the first study to show that variants associated with altered GDF15 levels segregate with disease in HG families, a finding that may explain familial susceptibility to HG. This study also shows that the GDF15 risk allele, rs16982345 [15], is associated with risk of recurrence, suggesting it also plays a role in non-familial HG. Approx- imately $80 \%$ of women who have HG will have it again in a subsequent pregnancy and this study identifies the first genetic risk factor associated with recurrence. GDF15 is highly expressed by the fetal component of the placenta [27], so future studies should focus on whether fetal genotype also plays a role in recurrence.

Additional supportive evidence of a role for GDF15 in HG comes from previous studies showing it plays a role in placentation [16], decreases prior to miscarriage [28], and causes loss of appetite in animal models [29]. GDF15 regulates food intake [19], and causes cachexia [18], a disease characterized by symptoms similar to HG. In addition, GDF15 is upregulated in early pregnancy when HG occurs [30], and serum levels of GDF15 are abnormally high in women hospitalized for HG [31].

Our findings linking GDF15 SNPs to familial HG and recurrence risk should be explored further to determine whether the associations can be replicated and potentially used for individualized counseling and therapy. In our study, less than $2 \%$ of women with the AA genotype at rs 16928345 had a recurrence of HG. Thus, genotyping this locus may help doctors counsel their patients on their risk of having HG again, which would help the patient with family planning and preparing for future HG pregnancies. Furthermore, the brainstem-restricted receptor for GDF15, GFRAL, was recently identified and the pathway is actively being studied to identify novel therapeutic strategies for weight gain (and weight loss) which may be applicable to HG [29]. Of particular clinical interest, inhibition of GDF15 restored appetite and weight gain in a 
mouse model of cancer cachexia [18]. In the future, a drug that decreases levels of GDF15, if safe during pregnancy, may be effective in treating women who carry susceptibility alleles for the condition, limiting the adverse maternal and fetal outcomes associated with HG. Finally, this study provides additional evidence suggesting GDF15 plays a role in the etiology of HG. Clinicians can now let their patients know there is promising evidence that the hormone GDF15 may play a role in causing HG. They can tell their patients they may carry genetic variants around the GDF15 locus that play a role in increasing their risk for $\mathrm{HG}$ as well as their risk for recurrence of HG. Physician scientists should focus on collecting HG patient and control DNA and biological samples early in pregnancy to compare GDF15 genotypes and GDF15 levels in cases and controls. This may lead to progress toward tools to help predict, diagnose, and treat this devastating pregnancy condition.

\section{Note}

This work has been presented, in part, at the International Conference on Hyperemesis Gravidarum, Windsor, England, 2017.

\section{Acknowledgements}

The authors thank the research participants for their contributions to this study. This work was funded, in part, by the Hyperemesis Education and Research Foundation and the Paul and Janis Plotkin Family Foundation.

\section{Conflict of Interest}

The authors declare that they have no conflict of interest.

\section{References}

[1] Clark SM, Costantine MM, Hankins GD. Review of NVP and HG and Early Pharmacotherapeutic Intervention. Obstet Gynecol Int 2012; 2012: 252676

[2] Verberg MF, Gillott D], Al-Fardan N et al. Hyperemesis gravidarum, a literature review. Hum Reprod Update 2005; 11: 527-539

[3] Källén B. Hyperemesis during pregnancy and delivery outcome: a registry study. Eur J Obstet Gynecol Reprod Biol 1987; 26: 291-302

[4] Jiang HG, Elixhauser A, Nicholas J, Steiner C, Reyes C, Bierman A. Care of Women in US Hospitals, 2000: HCUP Fact Book No. 3, no. 02-0044. Rockville, MD: Agency for Healthcare Research and Quality; 2002

[5] Chiossi G, Neri I, Cavazutti M et al. Hyperemesis gravidarum complicated by Wernicke's encephalopathy: background, case report and review of the literature. Obstet Gynecol Surv 2006; 61: 255-268

[6] Hill JB, Yost NP, Wendel GD jr. Acute renal failure in association with severe hyperemesis gravidarum. Obstet Gynecol 2002; 100: 1119-1121

[7] Adams RH, Gordon J, Combes B. Hyperemesis gravidarum. I. Evidence of hepatic dysfunction. Obstet Gynecol 1968; 31: 659-664

[8] Liang SG, Ooka F, Santo A et al. Pneumomediastinum following esophageal rupture associated with hyperemesis gravidarum. J Obstet Gynaecol Res 2002; 28: 172-175

[9] Fejzo MS, Poursharif B, Korst LM et al. Symptoms and pregnancy outcomes associated with extreme weight loss among women with hyperemesis gravidarum. J Women's Health 2009; 18: 1981-1987

[10] Fejzo MS, Magtira A, Schoenberg FP et al. Antihistamines and other prognostic factors for adverse outcome in hyperemesis gravidarum. Eur J Obstet Gynecol Reprod Biol 2013; 170: 71-76
[11] Fejzo MS, Magtira A, Schoenberg FP et al. Neurodevelopmental delay in children exposed in utero to hyperemesis gravidarum. Eur J Obstet Gynecol Reprod Biol 2015; 189: 79-84

[12] Dypvik J, Pereira AL, Tanbo TG et al. Maternal human chorionic gonadotrophin concentrations in very early pregnancy and risk of hyperemesis gravidarum: A retrospective cohort study of 4372 pregnancies after in vitro fertilization. Eur J Obstet Gynecol Reprod Biol 2018; 221: 12-16

[13] Zhang Y, Cantor R, MacGibbon K et al. Familial aggregation of hyperemesis gravidarum. Am J Obstet Gynecol 2011; 204: 230

[14] Colodro-Conde L, Jern P, Johansson A et al. Nausea and vomiting during pregnancy is highly heritable. Behav Genet 2016; 46: 481-491

[15] Fejzo MS, Sazonova OV, Sathirapongsasuti JF et al. Placenta and appetite genes GDF15 and IGFBP7 are associated with hyperemesis gravidarum. Nat Commun 2018; 9: 1178

[16] Moore AG, Brown DA, Fairlie WD et al. The transforming growth factorss superfamily cytokine macrophage inhibitory cytokine- 1 is present in high concentrations in the serum of pregnant women. J Clin Endocrinol Metab 2000; 85: 4781-4788

[17] Tsai VW, Macia L, Johnen $\mathrm{H}$ et al. TGF-b superfamily cytokine MIC-1/ GDF15 is a physiological appetite and body weight regulator. PLoS One 2013; 8: e55174

[18] Lerner L, Tao ], Liu Q et al. MAP3K11/GDF15 axis is a critical driver of cancer cachexia. J Cachexia Sarcopenia Muscle 2016; 7: 467-482

[19] Hsu JY, Crawley S, Chen M et al. Non-homeostatic body weight regulation through a brainstem-restricted receptor for GDF15. Nature 2017; 550: $255-259$

[20] Hyperemesis Education and Research Foundation. Online: www.helpher. org; last access: 07.08.2018

[21] Fejzo MS, Myhre R, Colodro-Conde L et al. Genetic analysis of Hyperemesis Gravidarum reveals association with intracellular calcium release channel (RYR2). Mol Cell Endocrinol 2017; 439: 308-316

[22] Li H, Durbin R. Fast and accurate short read alignment with BurrowsWheeler transform. Bioinformatics 2009; 25: 1754

[23] McKenna A, Hanna M, Banks E et al. The Genome Analysis Toolkit: a MapReduce framework for analyzing next-generation DNA sequencing data. Genome Res 2010; 20: 1297

[24] Hsu LA, Wu S, Juang IJ et al. Growth Differentiation Factor 15 May Predict Mortality of Peripheral and Coronary Artery Diseases and Correlate with Their Risk Factors. Mediators Inflamm 2017; 2017: 9398401

[25] Lappalainen T, Sammeth M, Friedländer MR et al. Transcriptome and genome sequencing uncovers functional variation in humans. Nature 2013; 501: 506-511

[26] Eriksson N, Johansson A, Hagstrom E et al. Genetic Effects on Levels of Growth Differentiation Factor 15 - A PLATO Genomics Study. Boston: Annual Meeting of the American Society of Human Genetics; 2013

[27] Segerer SE, Rieger L, Kapp M et al. MIC-1 (a multifunctional modulator of dendritic cell phenotype and function) is produced by decidual stromal cells and trophoblasts. Hum Reprod 2012; 27: 200-209

[28] Tong S, Marjono B, Brown DA et al. Serum concentrations of macrophage inhibitory cytokine 1 (MIC1) as a predictor of miscarriage. Lancet 2004; 363: 129-130

[29] Xiong J, Walker K, Min X et al. Long-acting MIC-1/GDF15 molecules to treat obesity: evidence from mice to monkeys. Sci Transl Med 2017; 9: eaan 8732

[30] Marjono AB, Brown DA, Horton KE et al. Macrophage inhibitory cytokine-1 in gestational tissues and maternal serum in normal and pre-eclamptic pregnancy. Placenta 2003; 24: 100-106

[31] Fejzo M, Arzy D et al.; 23andMe Research Team. Genetic Analysis of Hyperemesis Gravidarum. Windsor, England, International Colloquium on Hyperemesis Gravidarum, Oct. 2017. Online: https://vimeo.com/ 260389622; last access: 07.08.2018 